\begin{abstract}
Community colleges serve as the point of entry for the majority of Latinos in higher education, offering low-cost, smaller-scale educational opportunities in the communities where students live and providing the preparation for four-year colleges and universities that may have been lacking in their K-12 education. The challenges to community colleges in providing services to Latinos are great, but their potential to facilitate the achievement of Latinos is vast.
\end{abstract}

\title{
Latinos at Community Colleges
}

\author{
Magadelena Martinez, Edith Fernández
}

As former community college administrators, we approached the creation of this chapter by asking what types of information would have been helpful as we interacted with Latino students, faculty, and other administrators on a daily basis and attempted to facilitate student learning, adaptation, and academic success. Knowing that institutional needs and priorities vary depending on a number of internal and external variables, we offer an introduction to some of the most salient issues that affect Latino students attending community colleges as well as community colleges' ability to facilitate Latino student success.

Community colleges absorb a significant percentage of first-time college students. Two-year community colleges make up close to 50 percent of all colleges and universities, and their collective enrollment constitutes over 70 percent of all undergraduate students in higher education. Minority students represent 21 percent of all students enrolled in higher education, yet they constitute over 60 percent of the total enrollment in community colleges (Chronicle of Higher Education, 2002). (For the purposes of this discussion, the term minority refers to students who are African American, Latino, or Native American.) Low tuition, proximity to home, availability of evening courses, flexible schedules, remedial education, and open admissions are characteristics of community colleges that help to explain this phenomenal growth.

\section{Latino Participation in Community Colleges}

For Latinos, community colleges often represent a stepping-stone to a bachelor's degree. Latino students are far more likely to be enrolled in twoyear colleges than students from any other racial or ethnic group. Latinos 
represent 9 percent of all undergraduate students enrolled in higher education, yet close to 60 percent of Latino college enrollment is in two-year colleges (Chronicle of Higher Education, 2002). Within the Latino population, there are significant differences. For instance, Latinos of Mexican origin have the highest proportion of Latinos attending community colleges; almost half of Mexican American students attend two-year colleges (Fry, 2002). This has meaningful societal implications, because Latinos of Mexican descent represent close to 60 percent of the entire U.S. Latino population, and in several major cities, they represent a significant proportion of the population. States where there are significant numbers of Latinos depend on the educational preparedness of Latinos for economic and social stability. For these reasons, the overrepresentation of Latino students in community colleges has triggered a demand for research on the status of Latinos in community colleges, as well as the practices and policies that affect them. The purpose of this chapter is to provide a brief overview of the ways in which community colleges help Latino students achieve their educational and occupational goals, including strategies and programs that integrate family, community, and K-12 school systems.

\section{Educational Aspirations of Latino Students at Community Colleges}

For Latinos, community colleges occupy a unique position in higher education as sites for mining the social and cultural capital needed for upward social and economic mobility in the United States. When asked about their educational and occupational goals, Latino students overwhelmingly state at least a bachelor's degree as their intended goal. Research confirms that 50 to 87 percent of Latino students enrolled in community colleges aspire to transfer to a senior institution and complete a baccalaureate degree (Bensimon and Riley, 1984; Rendón, Justiz, and Resta, 1988). These studies point to the desire and motivation of Latinos to achieve higher academic goals that will eventually translate into occupational and career opportunities. Yet institutional, regional, and national studies point to the abysmally low percentage of Latino transfer rates to four-year institutions (Castaneda, 2002; Nora, 1993; Rendón, Justiz, and Resta, 1988; Rendón and Nora, 1989, 1994; Rendón and Valadez, 1993; Suarez, 2003). Studies show how Latinos' attendance at community colleges may adversely affect their chances of transferring, persistence, or completion of any type of degree (Brint and Karabel, 1989; Cohen and Brawer, 1996; Fry, 2002). Recent U.S. Department of Education statistics illuminate how Latino students are more likely to drop out if they begin their college studies at a two-year college (National Center for Education Statistics, 2000). Other studies show attrition rates for Latino students in community colleges as high as 80 percent (Rendón and Nora, 1989). Some suggest that high attrition rates are strongly correlated with students' socioeconomic and academic levels (Cohen and Brawer, 
1996; Tinto, 1987). Yet studies show that even after controlling for background, ability, and aspirations, students at community colleges are 10 to 18 percent more likely to drop out of college during the first two years than students at four-year colleges with similar backgrounds (Dougherty, 1992).

Latinos also lag in degree completion rates. Kane and Rouse (1995) found that half of the students who initially enrolled at two-year colleges never completed a postsecondary degree compared with the percentage of students who enroll in a four-year college as first-year students (cited in Fry, 2002). Although some suggest that the mission of community colleges is not exclusively to facilitate the graduation of all students, because many attend for professional development or vocational training, recent trends indicate that a large majority of students-in particular Latino studentswho attend community colleges aspire to eventually transfer to a senior institution. Community colleges must critically evaluate their role and examine why so few Latino students successfully navigate through their institutions to achieve their educational goals.

\section{The Community College Transfer Function}

Over the last twenty-five years, the transfer function of community colleges has declined significantly (Brint and Karabel, 1989; Cohen and Brawer, 1996; Rendón and Nora, 1994). Today, estimates of students who transfer to senior institutions range from 5 to 15 percent (Rendón and Nora, 1994). Brint and Karabel (1989) suggest that the increase in vocationalism not only marked a decline in the community college transfer function but also accentuated the stratification of higher education, relegating community colleges to the bottom of the hierarchy. The shift to a focus on vocational training has serious implications for how community colleges serve Latino students who enter two-year institutions with the expectation of transferring. Rendón (1999b) suggests that there is a disconnect between the expectations of Latino students and community college policy. Latino students attend community colleges as a gateway to senior institutions, expecting to complete transferable courses and receive the guidance and mentoring necessary to successfully navigate postsecondary institutions. Community college policy, on the other hand, primarily provides resources and support services for students interested in vocational programs, shortchanging the type of curriculum and student services needed to successfully transfer to senior institutions. Rendón (1999b) contends that the problem is not that Latino students lack ambition or ability to work; rather, they have not received the socialization, encouragement, and mentoring to be able to take advantage of higher education. To complicate matters, the lack of systematic study of transfer students and the many ways in which community colleges define a transfer student leave a gap in our understanding of how well community colleges prepare students for transfer. 
Nettles and Millett (1999) suggest that a common definition of what constitutes a transfer is needed across all community colleges in order to develop normative standards for institutions to use in monitoring their status and progress. They found that some colleges count as transfers only those students who receive an associate degree, while others include people who have completed a specified number of credit hours, and still others include anyone who ever attended. There have been efforts to devise a common definition of the transfer process. During the period from 1989 to 1993, the National Transfer Center grant program targeted community colleges with significant enrollments of low-income, black, and Latino students to implement an academic model for transfer purposes (Rendón and Nora, 1994). One of the concerns that surfaced was the need for effective measures to determine the success of transfer efforts. With the participation of the Center for the Study of Community Colleges (CSCC), the National Transfer Center program defined the transfer population as "those students who were first-time college attendees who enrolled in community college and earned, in a four-year period, at least twelve college-level credits and then enrolled in a four-year institution" (Rendón and Nora, 1994, p. 147). Those involved with the project suggested that "the transfer definition enables institutions to set transfer goals, include transfer in their strategic planning, and document student flow to determine how many students are benefiting from transfer efforts, what 'works' in transfer, and whether additional institutional efforts are needed" (Rendón and Nora, 1994, p. 149). It is unclear, however, whether this definition was adopted beyond the 164 community colleges that CSCC worked with during the program. Despite this limitation, several transfer studies illuminate the current status of Latinos and suggest some new directions for community colleges.

A comprehensive study that examined the transfer function at community colleges with high Latino student enrollments identified a number of barriers that deterred the transfer process (Rendón, Justiz, and Resta, 1988). Student-centered barriers included a lack of motivation and academic preparation; unfamiliarity with the costs and benefits of the higher education system; unwillingness to leave community and family; lack of family involvement in education; the necessity of having to work to help the family survive; not knowing they were capable of earning a degree; and failure to understand the consequences of changing programs and financial pressures. Institutional barriers included faculty resistance to advising students and low expectations for student academic achievement; lack of clear articulation agreements with senior institutions; and weak efforts to ease student academic and social integration (Rendón and Nora, 1994, p. 124).

A subsequent qualitative study (Suarez, 2003) identified factors that contributed to the transfer of Latino students from a California community college to a four-year state university. Suarez found that students' personal experiences, family struggles, and financial hardships often served as catalysts, motivating students to pursue their bachelor's degree. This "anything 
is possible" belief is likened to the "culture of possibility" found among high-achieving Chicanos and Chicanas who had graduated from selective institutions (Gandara, 1995). Suarez (2003) suggests that this finding underscores the importance of understanding students' background and the critical role it plays in shaping their educational decisions, actions, and resilience.

Another significant finding in Suarez's study (Suarez, 2003) was the importance of institutional commitment to the transfer function, which was largely mediated through strong external collaborations with senior institutions. These external relationships addressed only part of the puzzle; essential to Latino transfer success was also a sense of shared responsibility among students, faculty, and administrators, although Suarez suggests that faculty participation was minimal and was being showcased rather than faculty being full partners intimately involved in the planning and implementation of the transfer process. Numerous other studies have emphasized the importance of faculty-student interactions, in particular the potential positive or negative results such interactions have on the success of Latino students (Astin, 1982, 1993; Hurtado, Milem, Clayton-Pedersen, and Allen, 1998a, 1998b; Kuh, 1995). To date, the majority of transfer studies have focused on students' actions and behaviors, the utility of college transfer programs, faculty-student interactions, or faculty mentoring and advising. Missing from many of these studies is an examination of how cultural contexts are enacted and how they mediate institutional missions; also missing is an analysis of the roles that faculty, administrators, and students take on.

Rhoads's qualitative approach to organizational analysis examines the politics of culture and identity as revealed through the kinds of discourse and pedagogical strategies enacted at a community college with a high Latino student enrollment (Rhoads, 1999). To situate his analysis, he uses monoculturalism and multiculturalism as categories derived from his theoretical assumptions about culture, identity, and social structures. Monoculturalism is the belief that a singular culture prevails or ought to prevail within a society or organization. Education and pedagogical practices reinforce an authoritarian view, and students are viewed as static participants in the educational process. Multiculturalism is the belief that multiple cultural identities exist within a society and that it is the responsibility of the college to reflect the "different ways of knowing and cultural forms diverse peoples bring to educational institutions" (Rhoads, 1999, p. 115). When this perspective is used, diverse voices are included within the curriculum and within the organizing structures of the institutions. In his analysis, Rhoads found that the majority of faculty, administrators, and staff enacted a monocultural approach, while a small group enacted a multicultural approach to their roles within the community college. Faculty who enacted a multicultural perspective tended to encourage Mexican American students to see their education not only as a vehicle for economic progress but also as a tool for liberation; in other words, the cultivation of critical 
skills "not just to inform but to transform" their lives (Bensimon, 1994). Community college transfer programs that enacted the ideals of multiculturalism made positive contributions to increasing the transfer rates of participating students: in the program that Rhoads studied, the transfer rate for students was 13.5 percent compared with 9 percent for the overall student population at that college. The program focused on building collaborative relationships between English teachers and Mexican American counselors in order to provide a culturally based academic counseling program for students. Those that viewed their roles from a monocultural standpoint grounded their behaviors in assimilationist perspectives that forced diverse individuals to leave their cultural heritage behind in order to succeed. Rhoads (1999) suggests that many institutions have adopted a monocultural view and succinctly summarizes conditions at the majority of community colleges:

The challenge facing community colleges . . is helping faculty, staff, and students to recognize the interconnections between educational processes and student identities. Central to this challenge is coming to terms with the interconnectedness of culture, knowledge, and power. We need to recognize that teaching and learning is a contextualized process in which certain cultural forms become legitimized through their inclusion or delegitimized through their absence. This legitimization process has serious consequences for a student's sense of self and sense of cultural identity. Nowhere perhaps are these issues more relevant than in the context of the community college where more and more diverse students are seeking educational opportunities and social mobility. [p. 121]

If this study is any indication of the direction in which community colleges-in particular those with high minority enrollments-should go, then institutions need to pay closer attention to their cultural contexts and find sites where collaborative relationships can be developed, sustained, and replicated.

\section{Creating Relationship-Centered Community Colleges}

Community colleges have been criticized for failing to acknowledge or adapt to the diversity in their student populations, resulting in stubbornly low transfer rates and consistently high dropout rates (Shaw, Rhoads, and Valadez, 1999). It is essential that action steps at the institutional level focus on creating in-class and out-of-class learning environments that validate the academic abilities and efforts of diverse students. Espousing such validation places the onus on college faculty, counselors, and administrative staff to take a proactive role in reaching out to students to affirm them as capable of doing academic work and to support them in their academic 
endeavors and social adjustment (Rendón, 1999a). High attrition rates and low transfer rates indicate that community colleges must reevaluate their purpose and mission within the broader society. There is no disputing that more can and should be done to help facilitate Latino students realize their educational aspirations. Rendón (1999a) suggests, "community colleges must find ways to enter into relationships with entities concerned with the common work of educating diverse students and strengthening their communities" (p. 1). If community colleges are to change the way they do business and facilitate student success, they must become relationship-centered institutions that focus on internal and external collaboration with all stakeholders. External collaboration focuses on faculty and administrators preserving access and opportunity, helping to minimize K-12 barriers, and preparing students for baccalaureate degrees. Many community colleges have focused on developing relationshipcentered initiatives that can serve as models for other institutions interested in creating more inclusive colleges. Rendón (1999a) also puts forth the following recommendations for community colleges interested in creating relationship-centered institutions:

- Community college leaders, faculty, and staff should engage in collaborative analysis and planning to design collaborative community colleges based on the principles of multiculturalism and democracy.

- Community colleges should design validating teaching and learning environments that are relationship-centered, connecting faculty and students.

- Relationship-centered models that engage two-year colleges with feeder $\mathrm{K}-12$ schools should be created in order to design institutional outreach strategies (for example, early intervention, summer bridge programs, and mentoring programs) that target students in the early grades. These models should focus on eradicating access barriers, instilling the idea that college is a viable option, and ensuring that certain requirements are fulfilled in order to attend college.

- Relationship-centered models that involve community colleges learning more about the educational needs of their diverse student clientele should be developed and sustained in order to design instructional programs for students when and where they need them.

- Community colleges should work with local schools and business and industry to design models (school-to-work, youth apprenticeship, tech prep, career academies, and cooperative education) that prepare students to enter the workforce.

- Community colleges should enter into collaborative partnerships with fouryear institutions to facilitate the transfer process, establish articulation agreements, initiate Transfer Year Experience Programs at the four-year institutions, and ensure that students are able to attain bachelor's degrees and be poised to enroll in graduate and professional schools. 


\section{Programs That Support Latino Students in Achieving Their Educational Goals}

This section identifies community college programs that have adapted multicultural ideals that integrate family, community, and K-12 school systems; these programs can serve as models for institutions interested in creating relationship-centered collaborations.

Puente Program, University of California. The Puente Program is perhaps one of the most successful community college programs for Latino students. Initiated in 1981 as a Latino-specific program at Chabot College in Hayward, California, it is now in place in some fifty-five two-year colleges and thirty-six high schools in California. The goals of the program are high school retention and college preparation. Key components include intensive writing instruction, a focus on Latino literature, academic counseling and mentoring, and workshops that integrate family members. The program is premised on the belief that validation of students' life experiences is essential for academic success. Puente's validating teams of instructors, counselors, and mentors play an important role in promoting college access. A validation team provides students with information about what it takes to transfer and earn a degree from a four-year institution, an education plan, solid academic preparation, and knowledge about the socioeconomic payoffs of obtaining a higher education. This is a comprehensive undertaking that links the community to the community college and four-year institutions. A study of the Puente programs indicates that 81 to 90 percent of the 1994-95 entering cohort were still in school and in the program two years later. These retention rates are significantly higher than rates for those who did not participate in the program (Gandara, 1996).

Achieving a College Education (ACE) Program, Maricopa Community Colleges, Arizona. ACE is a collaborative $2+2+2$ (two years in high school, two years of community college, two years at a four-year college) program that was originally established in 1987. Its purpose is to increase the number of minority, economically disadvantaged, and at-risk students who attain baccalaureate degrees after successfully completing high school and associate degrees. ACE has successfully collaborated with high schools in two districts and with Arizona State University (ASU) to increase retention and graduation rates. ASU, in conjunction with South Mountain Community College, offers a transfer bridge program for students during their third or fourth summer in the program. The program provides enrollment in a university-level course and a seminar that provides transfer information and a university orientation, a one-week residence hall experience, and orientation for ACE parents (Rendón, 1999a).

Summer Scholars Transfer Institute (SSTI), Santa Ana College, California. SSTI is a joint project involving Santa Ana College, the Los Angeles Community College District, and the University of California at Irvine (UCI). The program serves 150 community college students each summer. SSTI is 
an eleven-day residential program in which students earn three hours of college credit in one of five courses. Students and faculty meet one month prior to the start of the institute. Students complete extensive reading assignments, participate in classroom activities that stress collaborative learning, and participate in evening study groups. UCI also arranges a transfer day when students meet individually with admissions staff to review their transcripts and discuss admissions requirements. About 95 percent of all students successfully complete the course. Through this program, Santa Ana College has doubled the number of underrepresented students transferring to the University of California. Statewide, Santa Ana College has improved its ranking from forty-fourth to ninth place in number of Chicano/Latino students transferring to the University of California (Rendón, 1999a).

Access to higher education can no longer be narrowly defined in terms of college enrollment. Community colleges must understand that retention, adaptation, and transfer are equally important access issues. Once students enroll in community colleges, they need access to progressive and sustained assistance to ensure that they stay enrolled and graduate from college. The three programs that we just described illustrate how community colleges can address the systemic problems that many Latino students face in higher education. Not only do these programs address practical issues associated with retention and transfer, but they also incorporate and build important connections between faculty, high schools, transfer universities, and Latinos' homes and communities. These programs point to the importance of going beyond intellectual development and attending to the social and personal development of community college students. Validation should be intentional, proactive, and systematic for community college students. There is a high need to build multiple forms of connections to create and sustain much-needed relationship-centered community colleges.

\section{Conclusion}

Latinos attend community colleges at a far greater rate than any other ethnic or racial minority. Community colleges have become the dominant educational vehicle of Latinos in pursuit of their dreams through higher education. Therefore, it is essential that we support Latinos from as early as possible in their higher education career. Simply put, policymakers and educational leaders must develop policies aimed at improving educational opportunities at all levels. Policies must support programs that attend to the cultural norms of the community and the political contexts of those communities in order to increase students' access to, enrollment in, and graduation from college. A cookie-cutter approach comprised of solely technical components is not enough.

Community colleges need to move from monoculturalism to multiculturalism. Community colleges must understand the students they serve, who are often low-income, working-class, academically underprepared, 
first-generation students, and, in most cases, ethnic or racial minorities. These populations of college students are a sharp contrast to those who attend four-year institutions and whose parents have attended college. Students' cultural beliefs and norms must be integrated into program curricula, teaching strategies, and educational resources. Early studies indicate that the enactment of multicultural initiatives has positive results on students' perceptions of their ability and academic attainment.

Establish completion and transfer standards and develop a culture that facilitates achievement of these standards. Currently, there are no national standards for community college completion. However, as states face budget deficits, many legislatures are seriously considering holding public higher education institutions to new completion and transfer standards. Community colleges can no longer wait. Using institutional data, they must examine completion and transfer rates, decide if these are acceptable levels of completion, and explain why or determine a rate that they should aspire to achieve. At this time, the public has no basis for gauging the quality of community college completion rates, because there are no established standards (Nettles and Millett, 1999). As many senior institutions begin to establish ceilings on the number of freshman they can enroll, state legislators are forcing senior institutions and community colleges to work together to meet the needs of students who are attending community college for their first two years of study. Institutions should begin to seriously consider establishing transfer and completion rates that meet the needs of the students who attend the institutions and of their communities.

Recognize the institution's validation team. Instructors, counselors, and institutional mentors, to name a few, are access agents who are responsible for guiding and moving students along the educational pathway. It is critical to move these institutional agents toward viewing themselves as a validating team (see Rendón, 1999a). Institutions should start by taking inventory and recognizing those practices currently in place that serve to validate students on both academic and interpersonal levels. It is important to recognize best practices that are unique to an institution in order to build the team's strengths. Equip the team with the knowledge, skills, and awareness needed to support their ongoing efforts to foster students' personal development and social adjustment.

The bottom line is that community colleges need to change how they do business. Latinos will continue to turn to higher education as a vehicle for upward social, political, and economic mobility, and our social institutions will depend on community colleges to prepare, train, and support citizens who can sustain a diverse democracy. Creating and sustaining multicultural institutions, establishing completion and transfer standards, supporting research on Latino students, and recognizing institutions' validation teams need to be top priorities for community colleges concerned with facilitating student success. 


\section{References}

Astin, A. W. Minorities in American Higher Education. (1st ed.) San Francisco: JosseyBass, 1982.

Astin, A. W. What Matters in College?: Four Critical Years Revisited. (1st ed.) San Francisco: Jossey-Bass, 1993.

Bensimon, E. M. (ed.). Multicultural Teaching and Learning: Strategies for Change in Higher Education. University Park, Penn.: National Center on Postsecondary Teaching, Learning, and Assessment, 1994.

Bensimon, E. M., and Riley, M. J. Student Predisposition to Transfer: A Report of Preliminary Findings. Los Angeles: Center for the Study of Community Colleges, 1984.

Brint, S. G., and Karabel, J. The Diverted Dream: Community Colleges and the Promise of Educational Opportunity in America, 1900-1985. New York: Oxford University Press, 1989.

Castaneda, C. "Transfer Rates Among Students from Rural, Suburban, and Urban Community Colleges: What We Know, Don't Know, and Need to Know." Community College Journal of Research and Practice, 2002, 26, 439-449.

Chronicle of Higher Education. "Chronicle of Higher Education Almanac." [http:// chronicle.com/free/almanac/2002/index.htm]. 2002.

Cohen, A. M., and Brawer, F. B. The American Community College. (3rd ed.) San Francisco: Jossey-Bass, 1996.

Dougherty, K. J. "Community Colleges and Baccalaureate Attainment." Journal of Higher Education, 1992, 63(2), 188-214.

Fry, R. Latinos in Higher Education: Many Enroll, Too Few Graduate. Washington, D.C.: Pew Hispanic Center, 2002. [http://www.pewhispanic.org/site/docs/pdf/latinos inhighereducation-sept5-02.pdf]. Retrieved May 5, 2003.

Gandara, P. C. Over the Ivy Walls: The Educational Mobility of Low-Income Chicanos. Albany: State University of New York Press, 1995.

Gandara, P. Puente Two-Year Evaluation. Davis: University of California, 1996.

Hurtado, S., Milem, J. F., Clayton-Pedersen, A., and Allen, W. R. Enacting Diverse Learning Environments: Improving the Climate for Racial/Ethnic Diversity in Higher Education. ASHE-ERIC Higher Education Report, vol. 26, no. 8. Washington, D.C.: Graduate School of Education and Human Development, George Washington University, 1998a.

Hurtado, S., Milem, J. F., Clayton-Pedersen, A., and Allen, W. R. "Enhancing Campus Climates for Racial/Ethnic Diversity: Educational Policy and Practice." Review of Higher Education, 1998b, 21(3), 279-302.

Kane, T. J., and Rouse, C. E. "The Community College: Educating Students at the Margin Between College and Work." Journal of Economic Perspectives, 9(1), Winter 1995, pp. 63-84.

Kuh, G. D. "The Other Curriculum: Out-of-Class Experiences Associated with Student Learning and Personal Development." Journal of Higher Education, 1995, 66(2), $123-155$.

National Center for Education Statistics. Descriptive Summary of 1995-96 Beginning Postsecondary Students: 3 Years Later. NCES 2000-154. Washington, D.C.: U.S. Department of Education, 2000. [http://nces.ed.gov/pubs2000/2000154.pdf]. Retrieved Jan. 20, 2004.

Nettles, M. T., and Millett, C. M. "Student Access in Community Colleges." A project of the W. K. Kellogg Foundation, American Association of Community Colleges, and Association of Community College Trustees. [http://www.aacc.nche.edu/Content/ NavigationMenu/ResourceCenter/Projects_Partnerships/Current/NewExpeditions/ IssuePapers/Student_Access_in_Community_Colleges.htm]. 1999. Retrieved Jan. 20, 2004. 
Nora, A. "Two-Year Colleges and Minority Students' Educational Aspirations." In J. Smart (ed.), Higher Education: Handbook of Theory and Research. Vol. 9. New York: Agathon Press, 1993.

Rendón, L. "Fulfilling the Promise of Access and Opportunity: Toward a Vision of Collaborative Community Colleges for the 21st Century." A project of the W. K. Kellogg Foundation, American Association of Community Colleges, and Association of Community College Trustees. [http://www.aacc.nche.edu/Content/ NavigationMenu/ResourceCenter/Projects_Partnerships/Current/NewExpeditions/ IssuePapers/Fulfilling_the_Promise_of_Access_and_Opportunity.htm]. 1999a. Retrieved Jan. 20, 2004.

Rendón, L. "Toward a New Vision of the Multicultural Community College for the Next Century." In R. A. Rhoads (ed.), Community Colleges as Cultural Texts. Albany: State University of New York Press, 1999b.

Rendón, L., Justiz, M. J., and Resta, P. Transfer Education in Southwest Border Community Colleges. Columbia: University of South Carolina, 1988.

Rendón, L., and Nora, A. "A Synthesis and Application of Research on Hispanic Students in Community Colleges." Community College Review, 1989, 17(1), 17-24.

Rendón, L., and Nora, A. "Clearing the Pathway: Improving Opportunities for Minority Students to Transfer." In L. Bjork (ed.), Minorities in Higher Education. Phoenix, Ariz.: Oryx Press, 1994.

Rendón, L., and Valadez, J. "Qualitative Indicators of Hispanic Student Transfer." Community College Review, 1993, 20(4), 27-37.

Rhoads, R. A. "The Politics of Culture and Identity: Contrasting Images of Multiculturalism and Monoculturalism." In K. M. Shaw, R. A. Rhoads, and J. Valadez (eds.), Community Colleges as Cultural Texts. Albany: State University of New York Press, 1999.

Shaw, K. M., Rhoads, R. A., and Valadez, J. (eds.). Community Colleges as Cultural Texts: Qualitative Explorations of Organizational and Student Culture. Albany: State University of New York Press, 1999.

Suarez, A. L. "Forward Transfer: Strengthening the Educational Pipeline for Latino Community College Students." Community College Journal of Research and Practice, 2003, 27, 95-117.

Tinto, V. Leaving College: Rethinking the Causes and Cures of Student Attrition. Chicago: University of Chicago Press, 1987.

MAGADELENA MARTINEZ is a doctoral student at the Center for the Study of Postsecondary Education at the University of Michigan.

EDITH FERNÁNDEZ is a doctoral student at the Center for the Study of Postsecondary Education at the University of Michigan. 